\title{
O PAPEL DO PROFESSOR DIANTE DA AFETIVIDADE
}

\author{
Rachel Moreira Ramos ELISIÁRIO ${ }^{1}$
}

Gleicione Aparecida Dias Bagne de SOUZA ${ }^{2}$

Recebido em: 02/10/2015 - Aprovado em: 17/04/2016 - Disponibilizado em: 30/07/2016

\begin{abstract}
Resumo
Este trabalho tem como objetivo principal chamar a atenção daqueles que têm em suas mãos a responsabilidade social da Educação, para o fato de que precisamos rever nossas posturas diante da fase inicial da vida escolar. Sabe-se que é na Educação Infantil que a criança adquire os primeiros preparos para o convívio social, tem as primeiras noções de valores morais e também, através de atividades apropriadas, aprimora suas capacidades cognitivas e motoras. O docente deve se comprometer com o processo ensino-aprendizagem possibilitando à criança, através de sua mediação e afetividade, desenvolver sua singularidade, conhecer a si mesma e ao mundo a seu redor, de uma maneira autônoma, crítica e consciente. É importante salientar que a relação interpessoal professor - aluno é fator determinante neste processo que é aberto e permanente. O papel da afetividade nesse processo é um elemento importante para aumentar a sua eficácia, pois esses fatores são concretos, históricos e trazem a bagagem que o meio lhes ofereceu. Essa teoria auxilia no planejamento do ensino levando em conta as características individuais, o contexto e as atividades propostas.

Palavras-chave: Papel do professor. Afetividade. Processo Ensino-aprendizagem.
\end{abstract}

\begin{abstract}
This work has a main objective to ask attention of whom that has in hands the social education responsibility, to the fact that we need to review our postures in front of the initial stage of the school life. According to the studies, it's in the childish education that the child acquires the first prepares to the social society, and has the first notions to the moral values and also improves the cognitive and motive accomplishments. The lecturer must have the compromise with the teaching-schooling process, allowing the child, through his mediation and affection, develop her peculiarity, know herself and the world around, in an autonomous, criticism and conscious way. It's important to accentuate that the relation among teacher-student is a determinant factor in this opened and permanent process. The affection function in this process is an important aspect to increase its efficacy, because the factors are tangible, historic bringing the results that the environment had offered. This theory helps in the planning, taking into account, the individual aspect, the context and thee proposal activities.
\end{abstract}

Keywords: Teacher Function, Affection, Teaching-Schooling Process.

\footnotetext{
${ }^{1}$ Pedagoga e Pós-graduada em Psicopedagogia Institucional e Clínica pelo Centro Universitário do Sul de MinasUNIS.

${ }^{2}$ Pedagoga, Mestre em Engenharia de Produção pela Universidade Federal de Santa Catarina e Doutora em Educação pela Universidade do Minho- Portugal, convalidado pela Universidade São Paulo- USP.
} 


\section{Introdução}

Pensar e sentir são ações indissociáveis. Esta é a ideia que a presente reflexão tentará imprimir e defender ao longo do texto, tendo como preocupação central transpô-la para o campo educacional.

Por que o papel da afetividade é tão importante para o processo de Ensinoaprendizagem? Haveria conhecimentos exclusivamente cognitivos? Se alguém acredita que sim, estará em concordância com a concepção centrada na justaposição dicotômica entre cognição e afetividade, embasada no princípio de que a razão e emoção constituem dois aspectos diferenciados no raciocínio humano. Se ao contrário concebe que há uma relação intrínseca entre os processos cognitivos e afetivos, acredita que o conhecimento dos sentimentos e das emoções requer ações cognitivas, da mesma forma que tais ações cognitivas pressupõem a presença de aspectos afetivos. Assim, no trabalho educativo cotidiano não existe uma aprendizagem meramente cognitiva, pois os alunos não deixam os seus sentimentos e relações interpessoais enquanto pensam.

Esse referencial fornece pistas importantes para o crescimento pessoal e profissional dos docentes, principalmente da educação infantil, que necessitam compreender o desenvolvimento da criança de uma maneira completa, e, principalmente o papel relevante que a escola tem na construção do sujeito.

Para isso, é de fundamental importância que o professor esteja consciente de sua responsabilidade, tome decisões de acordo com os valores sociais de sua época, e considere ainda, as condições de vida familiar, social e afetiva de seus alunos.

Apresentadas tais razões, adentra-se no objetivo do presente texto: refletir sobre o papel do professor quanto à afetividade no contexto educacional.

\section{Afetividade e cognição}

Henry Wallon (1989) sustenta a teoria de estreito entrelaçamento entre afetividade e cognição, e traz uma nova forma de conceber a emotividade, a inteligência e a gênese humana. Para o autor, o que possibilita o acesso da criança ao mundo simbólico são as manifestações afetivas que vão intermediar suas relações com o mundo através dos adultos e declara que, "nutrir a inteligência no primeiro ano de vida é nutrir o afeto".

A relação que caracteriza o ensinar e o aprender transcorre a partir de vínculos entre as pessoas e inicia-se no âmbito familiar. A base desta relação vincular é afetiva, pois é através de uma forma de comunicação emocional que o bebê mobiliza o adulto, garantindo assim os cuidados que necessita. Portanto, é o vínculo afetivo estabelecido 
entre o adulto e a criança que sustenta a etapa inicial do processo de aprendizagem.

Wallon explica que a emoção é social e epidêmica e a mãe é afetada pelo choro do bebê. A criança sobrevive graças à mobilização do outro pela emoção. A afetividade não é apenas uma das dimensões da pessoa: é também uma fase de desenvolvimento, a mais primitiva. A história da construção da pessoa se dará por uma sucessão pendular de movimentos dominantemente afetivos ou dominantemente cognitivos - não paralelos, mas integrados, isso significa que a afetividade depende, para evoluir, de conquistas realizadas no plano da inteligência.

Para Wallon, a afetividade é fator fundamental na constituição do sujeito. É entendida como instrumento de sobrevivência do ser humano.

Desde pequeno, ainda recém-nascido, o ser humano utiliza a emoção para comunicar-se com o mundo. $\mathrm{O}$ bebê, antes mesmo da aquisição da linguagem consegue estabelecer relação com a mãe, através de movimentos de expressão, no primeiro momento, fisiológica.

Para Wallon, a emoção e a afetividade têm grande importância, daí a elaboração de conceitos a partir do ato motor, da afetividade e da inteligência, no entanto, faz uma diferenciação entre emoção e afetividade: manifestações da vida afetiva. $\quad \mathrm{Na}$ linguagem comum costuma-se substituir emoção por afetividade, tratando os termos sinônimos. Todavia não o são. A afetividade é um conceito mais abrangente no qual se inserem várias manifestações (apud GALVÃO, 2003, p.61).

Dessa maneira a afetividade assume papel fundamental no desenvolvimento humano, determinando interesses e necessidades individuais da pessoa; é um domínio funcional, anterior à inteligência.

Com relação a este tema, estudos sociogenéticos e antropológicos comprovam que, desde os primórdios, a expressão das emoções foi de fundamental importância para a evolução do ser humano enquanto pessoa social.

"O longo aprendizado sobre emoções e afetos se inicia nas primeiras horas de vida de uma criança e se prolonga por toda sua existência" (ARANTES, 2003, p.23).

Wallon reconhece que a afetividade não é apenas uma das dimensões da pessoa:
Ela é também uma fase do desenvolvimento, a mais arcaica. O ser humano foi logo que saiu da vida puramente orgânica, um ser afetivo. Da afetividade diferenciou-se, lentamente, a vida racional. Portanto, no início da vida, afetividade e inteligência estão sincreticamente misturados, com predomínio da primeira (1992,p.90). 
Desta forma, a pessoa se constrói em um processo constituído por alternâncias entre períodos de predomínio de construção do sujeito (dominantemente afetivos) e de períodos de construção do objeto (dominantemente cognitivos).

Nos momentos
dominantemente afetivos do
desenvolvimento o que está
em primeiro plano é a
construção do sujeito, que se
faz pela interação com os
outros sujeitos; naqueles de
maior peso cognitivo, é o
objeto, a realidade externa,
que se modela, à custa da
aquisição das técnicas
elaboradas pela cultura.
Ambos os processos são, por
conseguinte, sociais, embora
em sentidos diferentes: no
primeiro, social é sinônimo
de interpessoal; no segundo,
é o equivalente de cultural
(DANTAS, 1992: p.91).

A afetividade, na psicogenética de Henry Wallon, (1992) representa uma dimensão de grande importância, tanto do ponto de vista da construção da pessoa como do conhecimento e perpassa por vários momentos: no início, é utilizada como meio de sobrevivência e comunicação, em seguida dos dois aos seis anos, representa um elemento marcante nas expressões e atitudes.

De acordo com o autor, o fato de a emoção ser "regressiva" e levar à ineficácia do funcionamento cognitivo, impõe que a educação da emoção deva fazer parte do trabalho educativo, o que determina a necessidade de um conhecimento profundo do seu modo de funcionamento por parte dos educadores.

É possível evidenciar no cotidiano das escolas, grandes limites no campo da dimensão afetiva, os quais se revelam por baixo índice de autoestima, insuficientes atitudes de respeito, amizade, socialização e interação entre algumas crianças, incidência de atitudes orais e físicas agressivas e omissão em relação aos alunos por parte de algumas famílias.

A intervenção pedagógica, empregada como procedimento, almeja a compreensão das manifestações infantis que aparecem nas atividades lúdicas propostas junto às crianças de uma Instituição de Educação Infantil. Por meio da observação, busca-se registrar e analisar, a partir da teoria estudada, os acontecimentos ocorridos durante as atividades. Wallon indica a observação como uma ferramenta básica para se ter acesso às diversas manifestações e expressões da criança em seu contexto. Afirma o autor, que só é possível entender as atitudes da criança se houver compreensão da trama do ambiente na qual ela está inserida.

No desenvolvimento do indivíduo, as necessidades afetivas tornam-se cognitivas, e a integração afetividade e inteligência permite à criança atingir níveis de evolução os mais elevados. Aos poucos, a linguagem passa a substituir a expressão corporal, a sensibilidade orgânica passa a ser substituída 
pela sensibilidade oral e o carinho é substituído pelo elogio.

\section{A afetividade na perspectiva de Vygotsky}

Vygotsky, (2003) como Wallon, (1989) também acredita que pensamento e afeto são indissociáveis e que só se pode compreender adequadamente o pensamento humano quando se compreende a sua base afetiva.

\begin{tabular}{|c|}
\hline 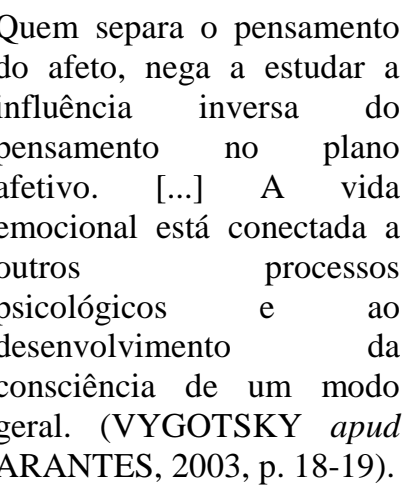 \\
\hline
\end{tabular}

Arantes, (2003) interpreta a teoria de Vygotsky sobre a importância da afetividade, afirmando que, o ser humano da mesma forma que aprende agir, a pensar e a falar, através da cultura e da interação com os outros, aprende a sentir, ou seja, a cognição e afeto se inter-relacionam e exercem influências recíprocas ao longo do seu desenvolvimento.

De acordo com os pressupostos da teoria histórico-cultural, o homem é produto do desenvolvimento de processos físicos e mentais, cognitivos e afetivos, internos e externos.
Diante disso, reafirma-se que a afetividade não é só importante na relação professor-aluno, mas também é primordial como estratégia pedagógica. Um professor que é afetivo com seus alunos estabelece uma relação de segurança, evita bloqueios afetivos e cognitivos, favorece o trabalho socializado, ajuda o aluno a superar erros e a aprender com eles; e, nessa perspectiva sociointeracionista, se o professor for afetivo a criança aprenderá a sê-lo.

\section{A afetividade na perspectiva de Piaget}

Piaget aponta que existe uma relação intrínseca, e ocorre paralelamente, entre o desenvolvimento afetivo e o desenvolvimento moral. (apud SALTINI, 1999).

Ainda no estágio sensório-motor, o sorriso infantil correspondido por um sorriso adulto, torna-se para a criança, um instrumento de diferenciação entre pessoas e objetos. De acordo com Piaget e Inhelder (1990), a criança começa a formar seus sentimentos morais a partir da sua relação afetiva com os pais. Ela estabelece os primeiros contatos e experimenta as primeiras vivências afetivas, que vão servindo de referência para orientar as relações com outras pessoas.

No estágio sensório-motor do desenvolvimento cognitivo, existe muito mais troca afetiva e contágios para a criança do que 
efetivamente diferenciação das pessoas e coisas.

O estágio pré-operatório marca outra etapa da evolução afetivo-social da criança: a mobilidade mental, o jogo simbólico e a linguagem favorecem novas interações e afetos.

No último estágio de desenvolvimento, do pensamento formal que corresponde à adolescência, o pensamento já está formado e se amplia com as interações afetivas, a mudança social e a construção de novos valores, entre outros.

\section{Afetividade no ambiente escolar}

Pode-se dizer que a qualidade da afetividade na relação professor-aluno é determinante para o processo ensinoaprendizagem e para o desenvolvimento do aluno, pois é primordial no processo educativo para dar subsídios à criança para que consiga manipular a realidade e estimular a função simbólica. Assim, essa afetividade está ligada à auto-estima e às formas de relacionamento entre aluno/professor e professor/aluno.

"Um professor que não seja afetivo com seus alunos fabricará uma distância perigosa, criará bloqueios e deixará de criar um ambiente rico em afetividade." (COSTA e SOUZA, 2006, p.12).

Para Costa e Souza (2006) o trabalho pedagógico voltado para o desenvolvimento da afetividade no processo educacional, deve considerar três processos interdependentes que implicam na capacidade da criança quanto à identificação e expressão de sentimentos, ao controle de impulsos e à redução de tensões: o emocional, o cognitivo e o comportamental.

A criança também precisa saber distinguir sentimento e ação, ler e interpretar indícios sociais, bem como compreender a expectativa dos outros, usar as etapas para resolver problemas, bem como compreender normas de comportamento.

Dessa maneira, um professor afetivo com seus alunos, que busca a aproximação e realiza sua tarefa de mediador entre eles e o conhecimento, atuará na zona de desenvolvimento proximal, isto é, na distância entre o nível de conhecimento real e aquele que os alunos poderão construir com sua ajuda. A afetividade passa então, a ser um estímulo que gerará a motivação para aprender.

No entanto, cabe ressaltar que a motivação para a aprendizagem depende das estratégias didáticas, da qualidade das intervenções do professor e também do modo como planeja e utiliza certos recursos em suas aulas.

Foi realizada uma pesquisa com a intenção de demonstrar como os fatores afetivos se apresentam na relação professoraluno e sua influência no processo de aprendizagem. 
Numa

perspectiva

teórica

fundamentalmente social, Vygotsky, (1994) defende a manifestação da afetividade na relação professor-aluno que se constitui elemento inseparável do processo de construção do conhecimento. E ao destacar a importância das interações sociais traz a ideia da mediação e da internalização como aspectos fundamentais para aprendizagem e defende que a construção do conhecimento ocorre a partir de um intenso processo de interação entre as pessoas. Segundo o autor, o processo de internalização envolve uma série de transformações que colocam em relação o social e o individual. Afirma que "todas as funções no desenvolvimento da criança aparecem duas vezes: primeiro, no nível social, e, depois no nível individual; primeiro entre pessoas (interpsicológica), e, depois, no interior da criança (intrapsicológica)" (1994, p. 75).

$\mathrm{Na}$ verdade, são as experiências vivenciadas com outras pessoas que irão marcar e conferir aos objetos um sentido afetivo, determinando, dessa forma, a qualidade do objeto internalizado. Nesse sentido, pode-se supor que, no processo de internalização, estão envolvidos não só os aspectos cognitivos, mas também os afetivos.

\section{A pesquisa}

Dessa maneira, foi realizada uma observação em uma classe com crianças de seis anos em média, e foi possível registrar a partir das interações entre o professor e o aluno durante as atividades que envolviam a linguagem escrita e oral, alguns aspectos afetivos que influenciavam a relação do aluno com a atividade, influenciando, de igual maneira, a aprendizagem.

$\mathrm{Na}$ referida pesquisa de campo foi possível verificar, também, através de observações do comportamento da professora, entrevista com alunos e professora, que a afetividade manifestava-se por meio de comportamentos posturais e verbais. Postura e conteúdo verbal - constituíram-se em fortes veículos de expressão da afetividade. Nas condições observadas, foi, através de ambas as categorias que os aspectos afetivos manifestaram-se na mediação professor/aluno.

Com relação às posturas da professora, o que mais se observou foi a frequência com que se mantinha próxima de seus alunos e a forma como os acolhia fisicamente, constituindo-se assim uma forma de interação extremamente afetiva, que amenizava a ansiedade, transmitia confiança e encorajavaos no processo de execução da atividade interferindo, particularmente na aprendizagem. Segundo DANTAS (1993), “é impossível alimentar afetivamente à distância”.

Tais comportamentos estabeleciam grande cumplicidade no processo de aprendizagem e foram extremamente 
valorizados pelo educandos, como se pode constatar através de seus comentários.

A entrevista com a professora baseouse em questões a respeito dos aspectos que mais mereciam a sua atenção, tais como: No processo de apropriação da linguagem escrita e oral e no questionamento de com o era o posicionamento dela a respeito da manifestação da dimensão afetiva nesse processo.

Ao observar os dados coletados, percebe-se que revelaram que nessa idade, os gestos posturais expressam grande parte da afetividade, embora a linguagem oral predomine nas interações em sala de aula e tenham desempenhado um papel fundamental nas relações observadas. $\mathrm{Na}$ verdade, as posturas corporais complementaram e deram maior significado ao que era dito oralmente. Quanto aos conteúdos verbais, observou-se que, pelas respostas dadas durante a entrevista com os alunos, eles preferiram, na maioria, as palavras de incentivo, coragem e confiança. Nesse sentido, infere-se que existiu, por parte da professora, maior preocupação com o processo de execução da atividade e não apenas com o resultado final.

Através das atitudes dos alunos, obtevese uma amostra de como eles veem, sentem e compreendem alguns aspectos do comportamento dessa professora e a influência destes comportamentos na aprendizagem. A partir dos dados coletados, foi possível, ainda, concluir que existem transformações importantes nas formas de expressão e mudanças significativas nos níveis de exigência afetiva. As formas de expressão que utilizam exclusivamente o corpo, como o toque, os olhares $\mathrm{e}$ as modulações da voz, vão ganhando maior complexidade. Nesse sentido, é possível concluir que a afetividade não se limita apenas às manifestações de carinho físico e de elogios superficiais.

$$
\begin{aligned}
& \text { Com o advento da função simbólica } \\
& \text { que garante formas de preservação } \\
& \text { dos objetos ausentes, a afetividade se } \\
& \text { enriquece com novos canais de } \\
& \text { expressão. Não mais restrita à troca } \\
& \text { de corpos, ela agora pode ser nutrida } \\
& \text { através de todas as possibilidades de } \\
& \text { expressão que servem também à } \\
& \text { atividade cognitiva.(DANTAS, 1993, } \\
& \text { p.75). }
\end{aligned}
$$

Os comentários dos alunos evidenciaram que a qualidade de interação professor/aluno traz um sentido afetivo para o objeto de conhecimento e influencia a aprendizagem do aluno.

Adequar a tarefa às possibilidades dos alunos, fornecer meios para que realizem a atividade confiando em sua capacidade, demonstrar atenção às suas dificuldades e problemas, são maneiras de comunicação afetiva.

A professora, por sua vez, demonstrou a preocupação de encorajar os alunos a investirem no próprio aprendizado, confiando na capacidade de cada um e fortalecendo a autoestima. Demonstrou também que o fato de ter consciência do entrelaçamento dos 
aspectos afetivos e cognitivos, trazia maior possibilidade de controlar e reverter sentimentos negativos, como também explorar de maneira positiva o desejo de aprender e o interesse em fazer.

O contato físico também apareceu como forma de interação afetiva, ocorrendo em vários momentos durante a realização da atividade, surgindo enquanto os alunos escreviam ou liam para a professora ou mesmo quando se aproximavam dela para desfazer alguma dúvida.

Pode-se observar que por meio de atividades lúdicas dirigidas e livres que contemplam a imaginação, a relação criança/criança, criança/professor, a manipulação de objetos, as cantigas infantis e ainda as brincadeiras, a criança vai evoluindo nos seus conhecimentos e se constituindo como pessoa humana.

A professora atuava com o objetivo de combater o excesso de ansiedade que surgia durante as atividades, buscando contagiar os alunos com sentimentos que tranquilizavam, encorajavam e os fortaleciam na execução dessas atividades. Medo, angústia, ansiedade e frustração são sentimentos que desgastam o aluno e "travam" o processo de aprendizagem. Demonstrando serenidade e tranquilidade, o professor reduz ou até elimina esses sentimentos, permitindo o que Dantas (1994) denomina de "destravamento" da atividade cognitiva.
Da mesma forma, é a partir da relação com o outro, através do vínculo afetivo que, nos anos iniciais, a criança tem, aos poucos, acesso ao mundo simbólico e, assim, conquista avanços significativos no âmbito cognitivo. Nesse sentido, para a criança, torna-se importante e fundamental o papel desse vínculo, que inicialmente apresenta-se na relação pai-mãe-filho e, muitas vezes, irmão(s). No decorrer do desenvolvimento, os vínculos afetivos ampliam-se e a figura do professor surge com grande importância na relação de ensino e aprendizagem, na época escolar.

Os dados apresentados parecem confirmar que existiram trocas afetivas. Foi possível encontrar no comentário e na observação, tanto de alunos como da professora, referências ao respeito, à colaboração, à valorização de cada um e o desejo de compreender o outro. Assim, quanto melhores forem as condições de se cultivarem sentimentos com estes, mais concretos e profundos serão os relacionamentos, e isso promoverá uma aprendizagem significativa.

É certo que nem sempre as relações entre as pessoas são permeadas pela compreensão e tranquilidade. A raiva, o medo, a ansiedade e a tristeza estão presentes nas interações sociais.

Deve-se ressaltar, no entanto, que na presente pesquisa, os dados coletados restringiram-se apenas às situações 
específicas de aprendizagem. Além disso, foi possível inferir, a partir da entrevista com a professora, que existe uma grande preocupação em trabalhar os sentimentos que influenciam negativamente no processo de aprendizagem, através de ações concretas para amenizar os efeitos nocivos que tais sentimentos provocam. Nesse sentido, tornase evidente que condições afetivas favoráveis facilitam a aprendizagem.

Considerando que o processo de aprendizagem ocorre em decorrência de interações sucessivas entre as pessoas, a partir de uma relação vincular, é, portanto, através do outro, que o indivíduo adquire novas formas de pensar e agir e, dessa forma constrói novos conhecimentos. E isso acontece

Nos momentos dominantemente afetivos do desenvolvimento. Em primeiro plano é a construção do sujeito, que se faz pela interação com os outros sujeitos; naqueles de maior peso cognitivo, é o objeto, a realidade externa, que se modela, à custa da aquisição das técnicas elaboradas pela cultura. Ambos os processos são, por conseguinte, sociais, embora em sentidos diferentes: no primeiro, social é sinônimo de interpessoal; no segundo, é o equivalente de cultura (DANTAS, 1992, p.91).

\section{Afetividade e o brincar}

Brincar é uma atividade universa, encontrada nos vários grupos humanos, em diferentes períodos históricos e estágios de desenvolvimento econômico.
Como toda atividade humana, o brincar constitui-se na interação de vários fatores que marcam determinado momento histórico sendo transformado pela própria ação dos indivíduos e por suas produções cultural e tecnológica.

Os jogos e a brincadeiras são, assim, transformados continuamente. Longe de promover unicamente uma conquista cognitiva, estas atividades envolvem emoções, afetividade, estabelecimento e ruptura de laços e compreensão da dinâmica interna que perpassa a ligação entre as pessoas. Um jogo ou brincadeira do qual participem mais de uma pessoa sempre implicam trocas, partilhas, confronto e negociações. A afetividade envolvida nesta ação pode adquirir nuanças variadas, traduzindo-se na alternância de momentos harmônicos e desarmônicos.

Nas atividades lúdicas, as crianças iniciam sua integração social, aprendem não só a conviver com os outros, mas também a situar-se no mundo que as cerca. Ao brincar, desenvolvem seu lado emocional e afetivo bem como suas aptidões cognitivas.

A criatividade das crianças possibilita mudar o final de uma história que não foi fácil suportar e o faz-de-conta propicia a elaboração de situações vividas que lhes foram excessivas, além disso, permite a elas descarregar nos objetos de suas brincadeiras sentimentos de angústia e agressividade. Dessa maneira, o brincar transforma-se não só 
em espaço da criação como um momento de elaboração de conflitos.

Brincar juntos reforça laços afetivos. É uma maneira de manifestar nosso amor à criança. A participação do adulto na brincadeira com a criança eleva o nível de interesse pelo enriquecimento que proporciona, pode também contribuir para os esclarecimentos de dúvidas referentes às regras das brincadeiras, estimulando assim os aspectos afetivos e cognitivos. A criança sente-se ao mesmo tempo prestigiada e desafiada quando o parceiro é um adulto e, este por sua vez pode levar a criança a fazer descobertas e a viver experiências que tornam o brincar mais estimulante e mais rico em aprendizado.

\section{Considerações finais}

Quando se entende que o processo de aprendizagem é social, foca-se o olhar para as interações e, os procedimentos tornam-se extremamente importantes. O que se diz, como se diz, em que momento e por que. Da mesma forma, o que se faz, como se faz, em que momento e por que, envolvem profundamente as relações professor/aluno, influenciando desta maneira, o processo ensino/aprendizagem. $\mathrm{O}$ comportamento do educador em sala de aula expressa suas intenções, crenças, valores, sentimentos e desejos que "afetam" cada aluno individualmente. Assim, tendo em vista a importância da afetividade deflagrada pelos resultados obtidos na pesquisa, conclui-se que há uma forte preocupação dos educadores em "afetar" positivamente seus alunos, oportunizando momentos e espaços adequados ao estabelecimento de interações sociais, capazes de promover o desenvolvimento do sujeito em todas as suas dimensões, ou seja, cognitiva, afetiva, motora e social. A afetividade desempenha um papel fundamental na constituição e funcionamento da inteligência, pois são os motivos, necessidades e desejos que dirigem o interesse da criança para conhecer e conquistar o mundo.

Se o profissional da Educação Infantil sempre atualizar seus conhecimentos teóricos, fundamentar sua prática, observar direta e objetivamente seus alunos poderá orientar o aprendizado no sentido de promover o desenvolvimento potencial de uma criança, tornando-o real. Como se constatou pelos estudos, o professor, dentro da sala de aula, é o principal mediador do processo ensinoaprendizagem. Ocupa uma função ímpar e privilegiada no desenvolvimento da criança e pode contribuir para o sucesso ou o fracasso do aluno na escola. Ele pode estabelecer vínculos afetivos muito fortes com e entre os alunos. Conclui-se, portanto, que o professor contagia e é contagiado pelos alunos. Wallon (1971, p.91) defende, em sua teoria, o caráter contagioso das emoções. "A emoção necessita 
suscitar reações similares em outrem e, (...) possui sobre o outro um grande poder de contágio."

Através de seu comprometimento profissional, das sondagens dos conhecimentos prévios da turma, das intervenções adequadas e pertinentes, dos elogios, das correções que faz, dos incentivos que dá, da ajuda na resolução de problemas, o professor pode ensinar muito a seus alunos. Nas atitudes de respeito à diversidade e limitações específicas de cada ser humano, bem como na valorização dos diferentes saberes e na disseminação de valores éticos e de solidariedade, conquista a admiração, a simpatia e o respeito de seus alunos.

Vimos na teoria e na prática, que as interações entre as docentes e os alunos não se limitam apenas aos aspectos cognitivos. Elas são impregnadas de afetividade e esta passa orientar o processo e pode tornar-se aliada de qualquer professor.

Portanto, analisar o processo de construção de novos conceitos, sejam eles matemáticos, linguísticos, artísticos e outros, a partir das interações em sala de aula direcionando o olhar para os aspectos afetivos inerentes à relação professor-aluno é um grande desafio.

Dessa maneira, faz-se necessário que as instituições de Educação Infantil, articuladas às políticas públicas sociais, constituam-se num espaço onde as formas de expressão da criança de zero a seis anos, dentre elas a linguagem verbal e corporal ocupem lugar privilegiado.

Num contexto lúdico e prazeroso de jogos e brincadeiras, onde as famílias e as equipes de educadores possam conviver intensa e construtivamente, cuidando e educando, objetiva-se promover o desenvolvimento individual, social e cultural destas crianças. Torna-se premente que exista uma progressiva articulação das atividades de comunicação e ludicidade com o ambiente escolarizado, no qual desenvolvimento, socialização, constituição de identidades e construção de conhecimentos possam ocorrer (BRASIL, 1999).

\section{Referências bibliográficas}

ARANTES, V. A. Afetividade na escola: alternativas teóricas e práticas. São Paulo: Atlas 2003.

\section{Brasil. Lei de Diretrizes e Bases da} Educação Nacional. Lei no ${ }^{\circ}$ 9.394/96, de 20 de dezembro de 1996.

COSTA, Keila Soares da; SOUZA, Keila Melo de. $O$ aspecto sócio-afetivo no processo ensino-aprendizagem na visão de Piaget, Vygotsky e Wallon. Disponível em: http: /www.educucaoonline.pro.br.Acesso em 26 março. 2015.

DANTAS, H. A afetividade e a construção do sujeito na psicogenética de Wallon. In: LA TAILLE, Y de; OLIVERIA, M. K. de; DANTAS, H. Piaget, Vygotsky, Wallon: teorias em discussão. São Paulo: Summus, 1992.

\section{GALVÃO, I. Henry Wallon: uma concepção dialética do desenvolvimento}


infantil. Petrópolis: Vozes, 2003. (Coleção

Educação e Conhecimento)

PIAGET, J.; INHELDER, B. A psicologia da criança. 11. ed. Rio de Janeiro:Bertrand

Brasil, 1990.

SALTINI, C.J.P. Afetividade e inteligência.

Rio de Janeiro: DP \& A, 1999.

VYGOTSKY, L. S. A formação social da mente. Rio de Janeiro: Guanabara Koogan, 1998.

Psicologia pedagógica. Porto

Alegre: Artmed, 2003.

WALLON, H. As origens do pensamento na criança. São Paulo: Manole, 1989. 